\section{Transparency of Sodium and Potassium Films in the Schumann Region}

THE remarkable transparency of alkali metal films reported by $R$. W. Wood ${ }^{1}$ is of considerable interest, on one hand in relation to the theory of electrons in metals and on the other in relation to spectroscopic technique, for these films are unique as filters ${ }^{2}$.

We have recently succeeded in depositing transparent films of sodium and potassium on fluorite cooled to liquid air temperature before the slit of a vacuum spectrograph. Photographs of the spectrum of the transmitted light establish that not only does sodium transmit from $2100 \mathrm{~A}$. to $1860 \mathrm{~A}$., as observed by Wood, but also that it transmits through the entire Schumann region to $1250 \mathrm{~A}$. (limit of fluorite). Experiments made with different film thicknesses indicate that there is some absorption in the neighbourhood of 1250-1400 A., and it seems reasonable to anticipate that the transparency of sodium does not extend very far beyond 10 volts. For potassium films (which transmit wave-lengths less than $3150 \mathrm{~A}$.) there is no observable transmission beyond $1400 \mathrm{~A}$., while there is evidence of weak absorption extending to between $1700 \mathrm{~A}$. and $1800 \mathrm{~A}$. Examples of the spectra are shown in Fig. 1.

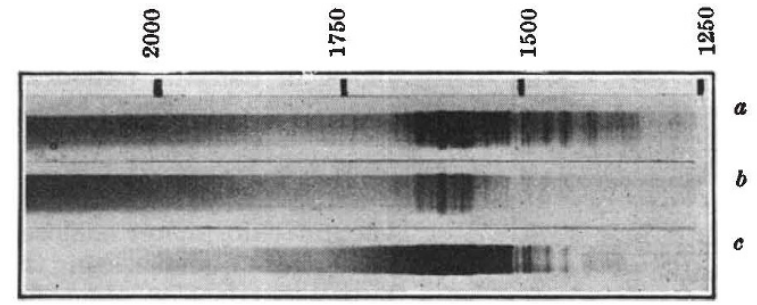

FIG. 1. Transmission of fluorite (a) without metal flm, $(b)$ with potassium flim, $(c)$ with sodium film.

A sodium film on fluorite is therefore an ideal filter to remove all visible and ultra-violet light of wavelength greater than $2100 \mathrm{~A}$. and to pass the entire Schumann region. A full account of our experiments will be published later, but it is appropriate now to indicate the conflict of the experimental results with the existing theory of the optical properties of metals ${ }^{3}$. According to Wilson's formulæ,

(i) for body-centred cubic lattices the absorption bands overlap and there is no transparency;

(ii) there is a sharp rise in the absorption at the low frequency end of an absorption band and slow decrease at the high frequency end.

Both of these conclusions are at variance with the experiments, so the theory cannot be applied in its present form to describe the optical properties of the alkali metals, which ought to afford the most favourable case for the quasi-free-electron model.

One of us (D. G. H.) is indebted to the National Research Council of Canada for scholarships to carry out this work.

W. H. Watson.

D. G. Hurst.

\section{McGill University, \\ Montreal.}

May $\mathbf{5 .}$

R. W. Wood, Phys. Rev., 44, 353 (1933).
H. M. O'Bryan, Rev. Sei. Inst., 6, 328 (1935).

See, for example, A. H. Wilson, Proc. Roy. Soc., A, 151, 280 (1935).
High Potassium Diet and the Survival of Adrenalectomized Rats

WHILE investigating the factors influencing the length of survival of rats after adrenalectomy, we found $^{1}$ that rats receiving liberal quantities of bread as a supplement to their usual diet lived many times longer than the controls fed on the stock ration alone. That this was only partly due to the high sodium chloride content of the bread ( 8 per cent by dry weight) seemed evident from the still markedly prolonged survival of rats receiving bread with a sodium chloride content as low as the stock diet, namely, 1 per cent. This diet, containing cereals, meat, molasses and vitamins (Purina Dog Chow), was taken well by unoperated animals. After adrenalectomy, however, the rats soon manifested an almost complete anorexia for the Purina, but those with access to bread in addition ate this well almost until the time of death. Consequently, these animals ingested more sodium chloride and a greater number of calories than the rats on Purina alone-facts favouring survival.

In explanation of the preference shown by the rats for bread, we suggested that this being a low residue food did not impair the characteristically diminished appetite of the adrenalectomized rat as did the high residue Purina. The fact that bread is a high carbohydrate food we emphasized as important in view of the well-known breakdown in carbohydrate metabolism in adrenal insufficiency.

Recent work of Zwemer and Truszkowski ${ }^{2}$ and also Allers, Nilson and Kendall ${ }^{3}$ appears to be of importance in the interpretation of our results. These workers have shown that a high potassium intake is detrimental to the life of adrenalectomized animals. In view of this finding, we have analyzed our diet and found the potassium content of the Purina to be 0.46 grams per cent, while that of the make of bread chiefly used was but 0.135 grams per cent. This result indicates that the low potassium content of the bread may have been a factor favouring survival in our rats so fed. Experiments are in progress to determine the relative importance of these factors.

\section{Department of Medicine, \\ University of Toronto,} Toronto.

R. A. CLEghorn.

G. A. McVicar.

${ }^{1}$ R. A. Cleghorn, S. M. M. Cleghorn, M. G. Forster and G. A. McVicar, J. Physiol., 86, 229 (1936).

2 R. L. Ziwemer and R. Truszkowski, Science. In the press, 1936. W. D. Allers, H. W. Nilson and E. C. Kendall, Proc. Staff Meet. Mayo Clinic, 11, 283 (1936).

\section{Humidity and Insect Metabolism}

EnTomologists have suggested that certain insects may show a greater rate of metabolism in dry air than in moist at the same temperature. They believe that such increased metabolism should cause a greater production of metabolic water, to compensate for evaporation from the insect's body, and maintain a constant ratio of water to dry matter at different atmospheric humidities. This increase in metabolic rate is assumed to occur in resting insects which are not moving actively. Buxton ${ }^{1}$ obtained results which indicated that, at $23^{\circ} \mathrm{C}$., the mealworm used up its reserves more rapidly in dry air than in moist, and kept the ratio of water to dry matter constant. As the body composition of mealworms is so variable, and as these results were obtained from rather small 